\title{
LETTERS
}

\section{Suggestions for managing in-flight emergencies}

Having responded recently to an in-flight emergency, I welcome this article ${ }^{1}$ and the helpful resources. I would add that physicians who respond to these emergencies should also consider that their role may not be finished once the airplane has landed. There will be some handover to other medical attendants or paramedics and possibly a request from either the patient or a relative for further information. While I was on the aircraft, an airline attendant took notes and recorded vital signs for the telemedicine sheet; however, the attending physician is not provided with a copy, which I would recommend that the airlines consider doing. A later follow-up request from a relative also means that obtaining written consent from the patient to provide medical details should be considered, which, in my case, was given to the spouse.

Some information about declaration of death while in flight would have been helpful in the article. My understanding is that the aircraft is required to land within the airspace where death is declared rather than proceeding to the destination.

I can also verify the statements about the limited utility of a stethoscope on board. Indeed, when I mentioned this to a physician colleague, he told me of his experience: on being unable to hear the heart sounds, he asked if the flight attendant would kindly ask the captain to turn off the engines for a minute. He was able to stop the attendant who was dutifully relaying the joking request.

\section{Anil Adisesh MB ChB MD MSc}

Occupational medicine physician, Dalhousie Medicine New Brunswick, St. John, NB

- Cite as: CMAJ 2018 June 25;190:E773. doi: $10.1503 / \mathrm{cmaj} .69286$

\section{Reference}

1. Kodama D, Yanagawa B, Chung J, et al. "Is there a doctor on board?": Practical recommendations for managing in-flight medical emergencies. CMAJ 2018;190:E217-22.

Competing interests: Recent provider of in-flight medical assistance. 